\title{
Treatment-Related Risk Factors for Development of Skin Breakdown in Subjects With Acute Respiratory Failure Undergoing Noninvasive Ventilation or CPAP
}

\author{
Wellington P Yamaguti PhD, Eliana V Moderno MSc, Sandra Y Yamashita, \\ Thelma GMC Gomes, Ana Lígia V Maida, Claudia S Kondo MSc, \\ Isabel CD de Salles MD, and Christina MM de Brito MD PhD
}

\begin{abstract}
BACKGROUND: Noninvasive ventilation (NIV) has been recognized as an effective strategy in preventing endotracheal intubation in subjects with acute respiratory failure (ARF). Some interface-related complications have also been recognized, such as skin breakdown (SB). The aim of this study was to determine the frequency of SB and identify potential treatment-related risk factors for its development in adults with ARF undergoing NIV or CPAP. METHODS: A cross-sectional study was conducted in a general hospital. Subjects were retrospectively enrolled in this study if they were $>18 \mathrm{y}$ old and developed ARF caused by any condition in which NIV or CPAP was indicated for at least one application for a period longer than $2 \mathrm{~h}$. The outcomes were the prevalence of SB and the evaluation of related risk factors. Data were extracted from the electronic medical records. A stepwise forward logistic regression model was used to identify independent risk factors for SB development. RESULTS: A total of 375 subjects (160 males) met the inclusion criteria and were enrolled in the study. Fifty-four subjects $(\mathbf{1 4 . 4 \% )})$ developed SB. The mean number of applications of NIV or CPAP carried out for $>2 \mathrm{~h}$ was higher in subjects with SB $(7.1 \pm 13.3 \mathrm{~h})$ than in those without SB $(4.4 \pm 13.3 \mathrm{~h})(P=.03)$. Subjects with SB also presented a higher total duration of NIV use $(44.6 \pm 118.5 \mathrm{~h})$ compared with subjects without $\mathrm{SB}(21.8 \pm 45.5 \mathrm{~h})(P=.01)$. Subjects who developed SB presented a higher use of oronasal mask $(92.6 \%)$ compared with the group that did not $(21.5 \%)(P<.001)$. CONCLUSIONS: In patients with ARF undergoing NIV or CPAP, oronasal mask use for $>26 \mathrm{~h}$ was independently associated with development of SB. Key words: noninvasive ventilation; acute respiratory failure; oronasal mask; total face mask; skin breakdown; wrap therapy; pressure ulcer. [Respir Care 2014;59(10):1530-1536. (C) 2014 Daedalus Enterprises]
\end{abstract}

\section{Introduction}

Noninvasive ventilation (NIV) has been recognized as an effective strategy in preventing endotracheal intubation and its complications in patients with acute respiratory failure (ARF). ${ }^{1-3}$ The advantages of the use of NIV over invasive mechanical ventilation include lower incidence of injury to the upper airways, laryngeal stenosis, and noso-

The authors are affiliated with the Rehabilitation Service, Physiotherapy Department, Hospital Sírio-Libanês, São Paulo, Brazil.

Dr Yamaguti presented preliminary study results in abstract form at the European Respiratory Society Annual Congress, held September 1-5, 2012, in Vienna, Austria. comial pneumonia, as well as a reduction in the need for sedative or paralytic drugs, hospital stay, and mortality. ${ }^{4,5}$ The main clinical indications for the use of NIV are directed to the treatment of COPD exacerbation, acute pulmonary edema, pulmonary infection in immunosuppressed subjects, and, in some specific cases, acute pancreatitis. ${ }^{6-12}$

\footnotetext{
The authors have disclosed no conflicts of interest.
}

Correspondence: Wellington P Yamaguti PhD, Rua Dona Adma Jafet, 91 (Centro de Reabilitação), CEP 01308-050 São Paulo, SP, Brazil. E-mail: wellington.psyamaguti@hsl.org.br or wellpsy@yahoo.com.br.

DOI: $10.4187 /$ respcare. 02942 
NIV has also been employed to prevent re-intubation in subjects who developed postextubation respiratory failure and to shorten the duration of invasive mechanical ventilation by facilitating weaning (earlier extubation). ${ }^{13,14}$

Although the use of NIV improves clinical outcomes, some complications and deleterious effects have also been recognized in clinical practice, such as aspiration, hemodynamic instability, dryness of secretions, and patientventilator asynchrony. ${ }^{15}$ Other adverse effects may also be related to use of the interface or to the pressure and flow titrated. One of the most serious interface-related complications is the development of skin breakdown (SB) in the regions of greatest contact pressure between the mask and the patient's skin. ${ }^{16}$ The presence of skin ulceration can increase discomfort reported by the patient, reducing the tolerance of the interface and the success rate of NIV.17-22

Previous studies have already underlined the importance of facial side effects of NIV in both children and adults by quantifying the incidence of SB in these populations. ${ }^{23,24}$ To our knowledge, there are no observational studies aimed to determine potential risk factors directly related to the treatment device and its application for the development of this complication in adult patients with ARF. Early identification of these factors may contribute to preventing the development of SB, thus optimizing the quality of care provided to subjects. The aim of this study was to determine the frequency of SB and identify potential treatmentrelated risk factors for its development in adults with ARF undergoing NIV or CPAP.

\section{Methods}

\section{Study Design and Population}

A cross-sectional study was conducted in the 40-bed ICU and 96-bed semi-ICU of Hospital Sírio-Libanês, a private nonprofit general hospital in São Paulo, Brazil. The study period for cases ranged from January to December 2011, during which time 414 subjects with ARF were considered for eligibility. Subjects were retrospectively enrolled in this study if they were $>18 \mathrm{y}$ old and developed respiratory failure caused by any condition in which NIV or CPAP was indicated for at least one application for a period longer than $2 \mathrm{~h} .{ }^{25}$ This latter inclusion criterion was adopted based on the rationale that constant pressure during a critical 1-2-h interval has been demonstrated to produce microscopic pathologic tissue changes, increasing the risk of pressure ulcer development. ${ }^{26}$ The diagnosis of ARF was made according to clinical history and physical examination. Additional criteria for enrollment included acute onset of moderate-to-severe dyspnea, clinical signs of increased work of breathing (breathing frequency $>25$ breaths/min, use of accessory respiratory muscles, or paradoxical breathing), and pulse oxygen sat-

\section{QUICK LOOK}

\section{Current knowledge}

Noninvasive ventilation (NIV) is associated with improved outcomes and lower mortality in exacerbations of COPD. Mask discomfort and skin breakdown (SB) are two of the most common reasons for NIV failure. The risk factors for SB are not well described.

\section{What this paper contributes to our knowledge}

SB was associated with the use of an oronasal mask and prolonged application of NIV. Stage I SB occurred in $13 \%$ of subjects and stage II SB in only $1.3 \%$ of subjects. A total face mask had a lower incidence of SB.

uration below $90 \%$ breathing at an $\mathrm{F}_{\mathrm{IO}_{2}}$ tension above 0.3 . Exclusion criteria were Glasgow coma scale below 8, death during hospitalization, previous presence of SB prior to admission in the study, and use of NIV for obstructive sleep apnea syndrome. When a patient was hospitalized in the ICU or semi-ICU on more than one occasion during the study period, only data from the first admission were used. NIV or CPAP was delivered via oronasal mask (ONM; Sure Seal, Hudson RCI, Research Triangle Park, North Carolina) or total face mask (TFM; Philips Respironics, Murrysville, Pennsylvania). In all subjects undergoing NIV or CPAP via ONM, a protective dermal sheet was applied over the nasal bridge (O'gel, Compress Produtos Médicos, São Paulo, Brazil), and the mask was secured with head straps, avoiding air leak or a tight fit. The subjects were ventilated with specific ventilators for NIV using bi-level positive airway pressure (BiPap Vision and BiPap Synchrony, Philips Respironics) or CPAP ventilatory modes (REMstar Auto C-Flex and Solo Plus LX, Philips Respironics). The study was approved by the ethics committee of Hospital Sírio-Libanês (HSL 2012-08).

\section{Outcomes and Data Collection}

The primary outcome of interest was the frequency of $\mathrm{SB}$, which was classified as stage I (prolonged erythema) and stage II (partial-thickness skin loss involving epidermis or dermis) according to the European Pressure Ulcer Advisory Panel and the American National Pressure Ulcer Advisory Panel. ${ }^{27}$ To determine SB status (stages I and II), the subject's skin was inspected after at least $45 \mathrm{~min}$ following NIV or CPAP withdrawal. SB stages III and IV were not considered because they were not observed in the present study.

Data were extracted from the electronic medical records of subjects enrolled in the study. The data collectors (SYY 
and TGMCG) were blinded to the study hypothesis and were not involved in the analysis or interpretation of the data. The electronic system contained all medical diagnosis, demographic, and clinical information for each patient. The following variables were evaluated as potential risk factors for SB development: age, gender, diagnosis, reason for the initiation of NIV or CPAP, interface type, ventilatory mode, number of applications carried out for $>2 \mathrm{~h}$, average duration of use per application, total duration of NIV or CPAP use, inspiratory positive airway pressure, expiratory positive airway pressure, and $\Delta \mathrm{P}$.

\section{Statistical Analysis}

Results are expressed as mean $\pm \mathrm{SD}$ for continuous variables. Chi-square and Fisher exact tests were used for analyses of dichotomous and categorical data. Continuous variables were compared using the Mann-Whitney test or the Student $t$ test. All variables with $P<.20$ were included in the multivariate logistic regression model. A stepwise forward logistic regression model was used to identify independent risk factors for SB development (dependent variable). Crude and adjusted odds ratios and the corresponding $95 \%$ CI were estimated. The Hosmer-Lemeshow test was used to assess the goodness of fit. Analyses were performed using SPSS 14 (SPSS, Chicago, Illinois).

\section{Results}

During this 12-month period, a total of 414 subjects admitted due to ARF were assisted with NIV or CPAP. Of that total, 375 subjects $(90.1 \%)$ met the inclusion criteria and were enrolled in the study. Fifty-four subjects (14.4\%) developed SB. Of those subjects, 49 (13.1\%) developed stage I SB, and only 5 subjects (1.3\%) developed stage II SB (Fig. 1). The demographic, anthropometric, and clinical characteristics are presented in Table 1. No difference was found between groups (with and without SB) with respect to age, gender, body mass index (BMI), and primary medical diagnosis. Half of the sample presented lung disease as the primary medical diagnosis.

The TFM was used for the majority of subjects included in this study $(68.3 \%)$. Subjects who developed SB presented a higher use of ONM $(92.6 \%)$ compared with subjects who did not $(21.5 \%, P<.001)$ (Table 2). The development of $\mathrm{SB}$ was observed in 50 subjects receiving NIV via ONM (42\%), but in only 4 subjects receiving NIV via TFM (1.6\%). Bi-level positive airway pressure was the main ventilatory mode applied in this study (97.3\%). Only 10 subjects $(2.7 \%)$ were assisted with CPAP. There was no difference in ventilatory modes between the two groups (Table 2).

The mean number of applications of NIV carried out for $>2 \mathrm{~h}$ was higher in subjects with SB $(7.1 \pm 13.3)$ than in

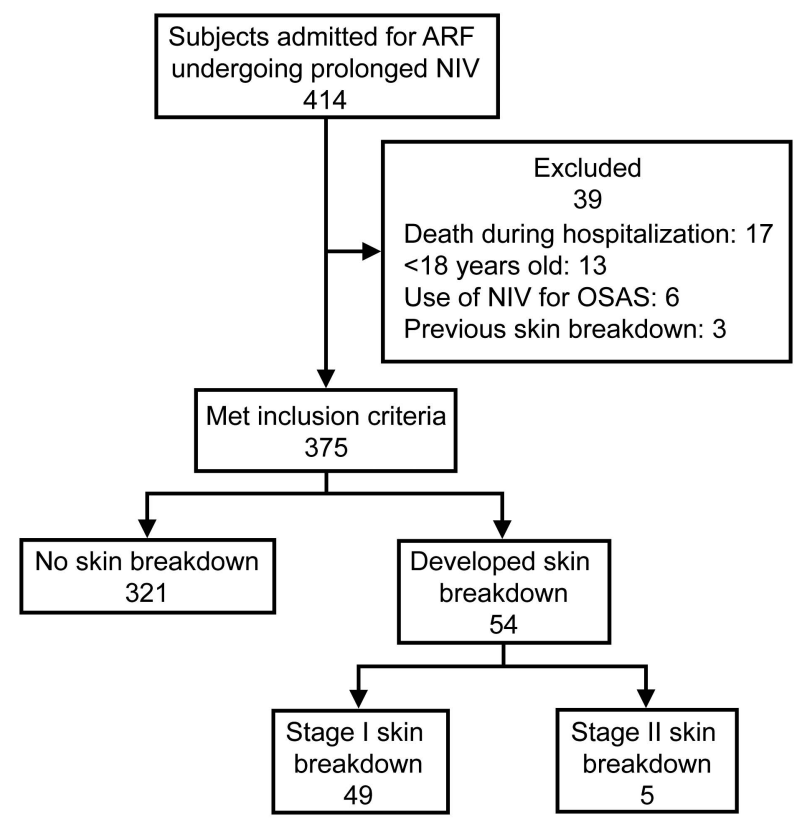

Fig. 1. Study flow diagram. $A R F=$ acute respiratory failure; NIV = noninvasive ventilation; OSAS = obstructive sleep apnea syndrome; SB = skin breakdown.

Table 1. Characteristics of the 375 Subjects Included in the Study With or Without SB

\begin{tabular}{lcccc}
\hline \hline \multicolumn{1}{c}{ Characteristics } & $\begin{array}{c}\text { With SB } \\
(n=54)\end{array}$ & $\begin{array}{c}\text { Without SB } \\
(n=321)\end{array}$ & $\begin{array}{c}\text { Total } \\
(n=375)\end{array}$ & $P$ \\
\hline Age, mean $\pm \mathrm{SD}(\mathrm{y})$ & $78.3 \pm 14.8$ & $75.1 \pm 15.8$ & & .17 \\
BMI, mean $\pm \mathrm{SD}\left(\mathrm{kg} / \mathrm{m}^{2}\right)$ & $25.2 \pm 2.7$ & $25.5 \pm 2.6$ & & .58 \\
Male gender, $n(\%)$ & $17(31.5)$ & $143(44.5)$ & $160(42.7)$ & .07 \\
Primary medical & & & & \\
$\quad$ diagnosis, $n(\%)$ & & & & \\
Pulmonary & $32(59.3)$ & $157(48.9)$ & $189(50.4)$ & .50 \\
Cardiological & $5(9.3)$ & $48(15)$ & $53(14.1)$ & .32 \\
Postsurgical & $4(7.4)$ & $32(10)$ & $36(9.6)$ & .77 \\
Oncological & $3(5.6)$ & $19(5.9)$ & $22(5.9)$ & .83 \\
Neurological & $2(3.7)$ & $19(5.9)$ & $21(5.6)$ & .76 \\
Others & $8(14.8)$ & $46(14.3)$ & $54(14.4)$ & .90 \\
& & & & \\
\hline
\end{tabular}

$\overline{\mathrm{SB}=\text { skin breakdown }}$

$\mathrm{BMI}=$ body mass index

those without SB $(4.4 \pm 7.5, P=.03)$. Subjects with SB also presented a higher total duration of NIV use $(44.6 \pm 118.5 \mathrm{~h})$ compared with subjects without SB $(21.8 \pm 45.5 \mathrm{~h}, P=.01)$. No significant difference in average duration of use per application was detected between groups $(4.9 \pm 2.8$ vs $4.8 \pm 2.6 \mathrm{~h}, P=.25)$. Regarding the parameters of ventilatory assistance, no difference in inspiratory positive airway pressure $(13.7 \pm 4.2$ vs $13.8 \pm 2.8 \mathrm{~cm} \mathrm{H}_{2} \mathrm{O}, P=.36$ ), expiratory positive airway pressure $\left(8.5 \pm 1.2\right.$ vs $\left.8.6 \pm 1.0 \mathrm{~cm} \mathrm{H}_{2} \mathrm{O}, P=.08\right)$, or $\Delta \mathrm{P}\left(5.7 \pm 2.7\right.$ vs $\left.5.4 \pm 2.1 \mathrm{~cm} \mathrm{H}_{2} \mathrm{O}, P=.30\right)$ was 
Table 2. Interfaces and Ventilatory Modes Used in Subjects With or Without SB

\begin{tabular}{|c|c|c|c|c|}
\hline & $\begin{array}{l}\text { With SB } \\
(n=54)\end{array}$ & $\begin{array}{l}\text { Without SB } \\
(n=321)\end{array}$ & $\begin{array}{c}\text { Total } \\
(n=375)\end{array}$ & $P$ \\
\hline \multicolumn{5}{|l|}{ Interface, $n(\%)$} \\
\hline Oronasal mask & $50(92.6)$ & 69 (21.5) & $119(31.7)$ & $<.001 *$ \\
\hline Total face mask & $4(7.4)$ & $252(78.5)$ & $256(68.3)$ & \\
\hline \multicolumn{5}{|l|}{$\begin{array}{c}\text { Ventilatory mode, } \\
n(\%)\end{array}$} \\
\hline CPAP & $3(5.5)$ & $7(2.2)$ & $10(2.7)$ & .12 \\
\hline BPAP & $51(94.5)$ & 314 (97.8) & 365 (97.3) & \\
\hline $\begin{array}{l}\text { * Statistically significant. } \\
\text { SB = skin breakdown } \\
\text { BPAP = bi-level positive }\end{array}$ & rway pressure. & & & \\
\hline
\end{tabular}

Table 3. Independent Risk Factors for Development of Skin Breakdown in Patients Undergoing NIV

\begin{tabular}{lcccc}
\hline \hline \multicolumn{1}{c}{ Variable } & Crude OR & Adjusted OR & $\begin{array}{c}\text { Adjusted OR } \\
95 \% \text { CI }\end{array}$ & $P$ \\
\hline $\begin{array}{l}\text { Interface } \\
\text { TFM }\end{array}$ & 1.00 & 1.00 & Reference & \\
$\quad$ ONM & 31.4 & 80.8 & $19.6-332.6$ & $<.001$ \\
Total NIV duration & & & & \\
$\quad \leq 26 \mathrm{~h}$ & 1.00 & 1.00 & Reference & \\
$>26 \mathrm{~h}$ & 1.8 & 8.62 & $2.3-32.1$ & .001 \\
& & & & \\
$\begin{array}{l}\text { Hosmer-Lemeshow test }=\text { chi-square }=0.016 . P=.90 . \\
\text { NIV }=\text { noninvasive ventilation }\end{array}$ & & & & \\
OR $=$ odds ratio \\
TFM $=$ total face mask \\
ONM $=$ oronasal mask
\end{tabular}

observed between subjects with and without SB, respectively.

The use of ONM with a total duration of NIV or CPAP of $>26 \mathrm{~h}$ (75th percentile) was independently associated with the development of SB in the final multivariate model (Table 3).

\section{Discussion}

Among the adverse effects related to mask ventilation, $\mathrm{SB}$, which occurs at the site of mask contact even after only a few hours of ventilation, is a frequent complication. ${ }^{15}$ In the present study, it was observed that the prevalence of stage I SB was $13.1 \%$ and that of stage II was $1.3 \%$ in a sample of subjects with ARF undergoing NIV. It was also observed that the total duration of NIV or CPAP and the use of ONM were considered independent risk factors for the development of SB in this population.

There are few studies that have been concerned with investigating the frequency of SB in subjects undergoing NIV. In a multi-center randomized study enrolling adult subjects, the effects of a prototype ONM on subject comfort and SB were compared with conventional ONMs. ${ }^{24}$ In this study, the prototype ONM evaluated was specifically designed to allow a more comfortable subject-mask interface where the mask was in contact with the nasal bridge. It was reported that the SB scores were significantly lower in the group assigned to receive NIV via prototype ONM (43\%) compared with the conventional ONM (100\%). In another study, the frequency of SB was determined in a population of children with obstructive sleep apnea, neuromuscular disorders, and cystic fibrosis undergoing NIV via nasal mask in chronic settings. ${ }^{23} \mathrm{SB}$ was observed in $48 \%$ of the subjects, with transient erythema in $18 \%$ (stage I), prolonged erythema in $23 \%$ (stage II), and skin necrosis in 3\% (stage III). The overall prevalence of SB was lower in our study (14.4\%), as well as stage I (13.1\%) and stage II $(1.3 \%)$ SB. In our study, no subject developed skin necrosis. A potential explanation for the difference in results observed between studies is that, in our study, a special dermal application material was provided to all subjects receiving NIV via ONM, probably reducing the prevalence of injury in our population. Other factors could be the difference in diagnosis, interface, duration of NIV (acute vs chronic), and age groups enrolled (children vs adults).

The incidence of subjective mask discomfort and intolerance may be one of the main reasons for NIV failure. ${ }^{28-31}$ SB development may be another aggravating factor that increases the patient's intolerance to the mask. In most cases, this can be treated with a simple mask adjustment or change of the interface. For this reason, different types of masks are available to overcome this problem. ${ }^{32}$ Antonaglia et $\mathrm{al}^{25}$ showed, in a randomized trial, that the use of a helmet to deliver NIV after $2 \mathrm{~h}$ of initial ONM use resulted in a better overall outcome, in terms of NIV failure, in comparison with subjects treated via ONM throughout the study. The authors observed that the high incidence of required intubation in the group that used ONM throughout the study was due to intolerance to the device, potentially caused by skin damage. In the present study, ONM use was considered an independent risk factor for the development of SB. Our data also demonstrated that the occurrence of SB was observed in only $1.6 \%$ of the subjects receiving NIV via TFM. NIV delivered via TFM has been proposed as an intervention to reverse ARF, and its use has been associated with better tolerance and comfort compared with an ONM. ${ }^{33-35}$ These findings reinforce the importance of recommending the use of interfaces that generate less pressure against the face (ie, TFM or helmet) ${ }^{36}$ for subjects who need prolonged NIV to prevent the development of SB, increasing the compliance and success of NIV. Furthermore, in patients who require prolonged intermittent mandatory ventilation, rotating the use of different types of masks may be another strategy for decreas- 


\section{Skin Breakdown in SubJects Undergoing NIV}

ing these problems. ${ }^{37}$ The need to provide equipment that minimizes the risk of adverse events is also a concern in preventing pressure ulcers in bedridden patients. In a prospective cohort study conducted in a surgical ICU, the incidence of pressure ulcers was monitored in a sample of critically ill subjects using two different support surfaces. The results demonstrated that critically ill subjects placed on low air loss beds with microclimate management had a lower pressure ulcer incidence than those placed on integrated powered air pressure redistribution beds. ${ }^{38}$

Our findings reveal that the total duration of NIV or CPAP use is another treatment-related risk factor independently associated with the development of SB. In a previous study, it was demonstrated that the SB score in a group of subjects undergoing NIV via ONM was $1.75 \pm 0.9$ after 24 h. ${ }^{24}$ When these subjects were followed for $48 \mathrm{~h}$, the SB score increased to $2.1 \pm 0.9(20 \%)$, suggesting that an NIV period of $\sim 24 \mathrm{~h}$ is associated with increased risk of skin injury. In another study involving trauma subjects with ARF, the incidence of SB was $\sim 70 \%$ in those subjects ventilated continuously via ONM for $>48 \mathrm{~h} .{ }^{39}$ In the present study, individuals receiving NIV for a period longer than $26 \mathrm{~h}$ presented 1.8 times more risk of developing SB than individuals undergoing NIV for a shorter period. These findings reinforce the hypothesis that the risk of development of SB in subjects undergoing NIV is timedependent. It is important to note that all individuals included in the present study received NIV for a continuous period of at least $2 \mathrm{~h}$. A previous study investigating risk factors for the development of pressure ulcers determined that the application of constant pressure for 1-2 $h$ was sufficient to cause tissue damage and cell death. ${ }^{26}$

Because air leaks may reduce the efficiency of NIV by reducing the patient's tolerance and increasing patientventilator asynchrony, the ONM is usually tightly sealed to the skin. However, if the mask pressure against the face exceeds the skin capillary pressure, impairing tissue perfusion, this can cause SB. ${ }^{36}$ During the application of CPAP, air leaks are less problematic because the pressure is constant and does not require a very tight-fitting mask adjustment. On the other hand, during bi-level positive airway pressure ventilation, the pressure applied switches from a high level to a lower level. For these reasons, it could be expected that ventilatory modes that impose higher levels of respiratory pressures would be associated with greater risk of developing skin lesions. Furthermore, higher values of respiratory pressures (level of inspiratory positive airway pressure, expiratory positive airway pressure, and $\Delta \mathrm{P}$ ) could be considered another treatment-related risk factor for the development of SB. Despite these factors, the ventilatory mode and its level of pressure applied did not seem to influence the occurrence of SB in our population once the mask was properly fitted. These findings were also observed in previous studies. ${ }^{24,40}$ Another factor that could influence the development of SB is BMI. Our patients presented a mean BMI of $25.2 \mathrm{~kg} / \mathrm{m}^{2}$ (with $\mathrm{SB}$ ) and 25.5 $\mathrm{kg} / \mathrm{m}^{2}$ (without $\mathrm{SB}$ ), similar to previous studies using different interfaces $\left(24.5-25.6 \mathrm{~kg} / \mathrm{m}^{2}\right) .{ }^{25,41}$ It could be expected that individuals with higher BMI would need a higher clamping pressure of the mask against the face. However, in the present study, BMI was not shown to be a risk factor for the development of SB.

A limitation of the present study is that the results presented were guided by data analysis from a single hospital. Despite this, the interpretations made here can be extrapolated to other contexts involving institutions having the same epidemiological profile of subjects with ARF, the same resources and equipment available, and characteristics of general and private hospitals. It is important to reinforce that this study is limited to the investigation of risk factors related to treatment. Other patient-related factors, such as nutritional status, diabetes, other comorbidities, hydration, medications, and skin diseases, were not investigated in this study. Another limitation of this study is the fact that we did not analyze the risk of SB development caused by the use of nasal masks or other models of ONMs. Therefore, these data cannot be extrapolated to other specific interfaces designed for home NIV. Finally, we did not evaluate the comfort score during NIV, so we cannot establish a relationship between the development of SB and discomfort in the present study. The practical implications arising from these results are focused on the need for identification of the frequency of SB and associated treatment-related risk factors for its development to contribute to a safer use of this treatment modality. In addition, the ability to provide better patient comfort while reducing skin lesions might enable NIV to be used successfully in clinical practice. Considering that the highest prevalence of SB is associated with ONM use in subjects with longer periods of NIV or CPAP, we recommend that TFM may be used in subjects expected to receive NIV or CPAP. Another strategy that may be employed is the periodic rotation of interfaces, alternating the use of ONM with TFM. In conclusion, the use of ONM and a total duration of NIV or CPAP of $>26 \mathrm{~h}$ were independently associated with the development of SB in patients with ARF.

\section{REFERENCES}

1. Girou E, Schortgen F, Delclaux C, Brun-Buisson C, Blot F, Lefort Y, et al. Association of noninvasive ventilation with nosocomial infections and survival in critically ill patients. JAMA 2000;284(18): 2361-2367.

2. Plant PK, Owen JL, Elliott MW. Early use of non-invasive ventilation for acute exacerbations of chronic obstructive pulmonary disease on general respiratory wards: a multicentre randomised controlled trial. Lancet 2000;355(9219):1931-1935.

3. Auriant I, Jallot A, Hervé P, Cerrina J, Le Roy Ladurie F, Fournier $\mathrm{JL}$, et al. Noninvasive ventilation reduces mortality in acute respi- 


\section{Skin Breakdown in SubJects Undergoing NIV}

ratory failure following lung resection. Am J Respir Crit Care Med 2001;164(7):1231-1235.

4. Hess DR. Noninvasive positive-pressure ventilation and ventilatorassociated pneumonia. Respir Care 2005;50(7):924-929; discussion 929-931.

5. Tomii K, Seo R, Tachikawa R, Harada Y, Murase K, Kaji R, et al. Impact of noninvasive ventilation (NIV) trial for various types of acute respiratory failure in the emergency department; decreased mortality and use of the ICU. Respir Med 2009;103(1):67-73.

6. Brochard L, Mancebo J, Wysocki M, Lofaso F, Conti G, Rauss A, et al. Noninvasive ventilation for acute exacerbations of chronic obstructive pulmonary disease. N Engl J Med 1995;333(13):817-822.

7. Confalonieri M, Aiolfi S, Gandola L, Scartabellati A, Della Porta R, Parigi P. Severe exacerbations of chronic obstructive pulmonary disease treated with BiPAP by nasal mask. Respiration 1994;61(6): 310-316.

8. Marvisi M, Brianti M, Marani G, Turrini G, Zambrelli P, Ajolfi C, Delsignore R. Acute antiarrhythmic effects of bi-level positive airway pressure ventilation in subjects with acute respiratory failure caused by chronic obstructive pulmonary disease: a randomized clinical trial. Respiration 2004;71(2):152-158.

9. Gray A, Goodacre S, Newby DE, Masson M, Sampson F, Nicholl J, 3CPO Trialists. Noninvasive ventilation in acute cardiogenic pulmonary edema. N Engl J Med 2008;359(2):142-151.

10. Valipour A, Cozzarini W, Burghuber OC. Non-invasive pressure support ventilation in subjects with respiratory failure due to severe acute cardiogenic pulmonary edema. Respiration 2004;71(2):144151.

11. Razlaf P, Pabst D, Mohr M, Kessler T, Wiewrodt R, Stelljes M, et al. Non-invasive ventilation in immunosuppressed subjects with pneumonia and extrapulmonary sepsis. Respir Med 2012;106(11):15091516.

12. Jaber S, Chanques G, Sebbane M, Salhi F, Delay JM, Perrigault PF, Eledjam JJ. Noninvasive positive pressure ventilation in subjects with respiratory failure due to severe acute pancreatitis. Respiration 2006;73(2):166-172.

13. Ferrer M, Valencia M, Nicolas JM, Bernadich O, Badia JR, Torres A. Early noninvasive ventilation averts extubation failure in patients at risk: a randomized trial. Am J Respir Crit Care Med 2006;173(2): 164-170.

14. Nava S, Ambrosino N, Clini E, Prato M, Orlando G, Vitacca M, et al. Noninvasive mechanical ventilation in the weaning of patients with respiratory failure due to chronic obstructive pulmonary disease: a randomized, controlled trial. Ann Intern Med 1998;128(9): 721-728.

15. Gay PC. Complications of noninvasive ventilation in acute care. Respir Care 2009;54(2):246-257; discussion 257-258.

16. Racca F, Appendini L, Berta G, Barberis L, Vittone F, Gregoretti C, et al. Helmet ventilation for acute respiratory failure and nasal skin breakdown in neuromuscular disorders. Anesth Analg 2009;109(1): 164-167.

17. Navalesi P, Fanfulla F, Frigerio P, Gregoretti C, Nava S. Physiologic evaluation of noninvasive mechanical ventilation delivered with three types of masks in subjects with chronic hypercapnic respiratory failure. Crit Care Med 2000;28(6):1785-1790.

18. Navalesi P, Costa R, Ceriana P, Carlucci A, Prinianakis G, Antonelli $\mathrm{M}$, et al. Non-invasive ventilation in chronic obstructive pulmonary disease subjects: helmet versus facial mask. Intensive Care Med 2007;33(1):74-81

19. American Thoracic Society, European Respiratory Society, European Society of Intensive Care Medicine, Société de Réanimation de Langue Française. International Consensus Conferences in Intensive Care Medicine: noninvasive positive pressure ventilation in acute respiratory failure. Am J Respir Crit Care Med 2001;163(1):283291.

20. Glerant JC, Rose D, Oltean V, Dayen C, Mayeux I, Jounieaux V. Noninvasive ventilation using a mouthpiece in subjects with chronic obstructive pulmonary disease and acute respiratory failure. Respiration 2007;74(6):632-639.

21. Hilbert G, Clouzeau B, Nam Bui H, Vargas F. Sedation during non-invasive ventilation. Minerva Anestesiol 2012;78(7):842-846.

22. Pisani L, Carlucci A, Nava S. Interfaces for noninvasive mechanical ventilation: technical aspects and efficiency. Minerva Anestesiol 2012;78(10):1154-1161

23. Fauroux B, Lavis JF, Nicot F, Picard A, Boelle PY, Clément A, Vazquez MP. Facial side effects during noninvasive positive pressure ventilation in children. Intensive Care Med 2005;31(7):965-969

24. Gregoretti C, Confalonieri M, Navalesi P, Squadrone V, Frigerio P, Beltrame F, et al. Evaluation of patient skin breakdown and comfort with a new face mask for non-invasive ventilation: a multi-center study. Intensive Care Med 2002;28(3):278-284.

25. Antonaglia V, Ferluga M, Molino R, Lucangelo U, Peratoner A, Roman-Pognuz E, et al. Comparison of noninvasive ventilation by sequential use of mask and helmet versus mask in acute exacerbation of chronic obstructive pulmonary disease: a preliminary study. Respiration 2011;82(2):148-154.

26. Breuls RG, Bouten CV, Oomens CW, Bader DL, Baaijens FP. Compression induced cell damage in engineered muscle tissue: an in vitro model to study pressure ulcer aetiology. Ann Biomed Eng 2003; 31(11):1357-1364.

27. European Pressure Ulcer Advisory Panel, National Pressure Ulcer Advisory Panel. Prevention and treatment of pressure ulcers: quick reference guide. 2009. http://www.epuap.org/guidelines/Final_Quick _Prevention.pdf. Accessed May 14, 2014.

28. Antonelli M, Pennisi MA, Pelosi P, Gregoretti C, Squadrone V, Rocco $\mathrm{M}$, et al. Noninvasive positive pressure ventilation using a helmet in subjects with acute exacerbation of chronic obstructive pulmonary disease: a feasibility study. Anesthesiology 2004;100(1):16-24.

29. Conti G, Antonelli M, Navalesi P, Rocco M, Bufi M, Spadetta G, Meduri GU. Noninvasive vs. conventional mechanical ventilation in subjects with chronic obstructive pulmonary disease after failure of medical treatment in the ward: a randomized trial. Intensive Care Med 2002;28(12):1701-1707.

30. Squadrone E, Frigerio P, Fogliati C, Gregoretti C, Conti G, Antonelli $\mathrm{M}$, et al. Noninvasive vs invasive ventilation in COPD subjects with severe acute respiratory failure deemed to require ventilatory assistance. Intensive Care Med 2004;30(7):1303-1310.

31. Kramer N, Meyer TJ, Meharg J, Cece RD, Hill NS. Randomized, prospective trial of noninvasive positive pressure ventilation in acute respiratory failure. Am J Respir Crit Care Med 1995;151(6):17991806.

32. Sferrazza Papa GF, Di Marco F, Akoumianaki E, Brochard L. Recent advances in interfaces for non-invasive ventilation: from bench studies to practical issues. Minerva Anestesiol 2012;78(10):11461153.

33. Chacur FH, Vilella Felipe LM, Fernandes CG, Lazzarini LC. The total face mask is more comfortable than the oronasal mask in noninvasive ventilation but is not associated with improved outcome. Respiration 2011;82(5):426-430

34. Holanda MA, Reis RC, Winkeler GF, Fortaleza SC, Lima JW, Pereira ED. Influence of total face, facial and nasal masks on short-term adverse effects during noninvasive ventilation. J Bras Pneumol 2009; 35(2):164-173.

35. Criner GJ, Travaline JM, Brennan KJ, Kreimer DT. Efficacy of a new full face mask for noninvasive positive pressure ventilation. Chest 1994;106(4):1109-1115. 


\section{Skin Breakdown in SubJects Undergoing NIV}

36. Nava S, Navalesi $\mathrm{P}$, Gregoretti C. Interfaces and humidification for noninvasive mechanical ventilation. Respir Care 2009;54(1):7184.

37. Fraticelli AT, Lellouche F, L'her E, Taillé S, Mancebo J, Brochard L. Physiological effects of different interfaces during noninvasive ventilation for acute respiratory failure. Crit Care Med 2009;37(3): 939-945.

38. Black J, Berke C, Urzendowski G. Pressure ulcer incidence and progression in critically ill subjects: influence of low air loss mattress versus a powered air pressure redistribution mattress. J Wound Ostomy Continence Nurs 2012;39(3):267-273.
39. Beltrame F, Lucangelo U, Gregori D, Gregoretti C. Noninvasive positive pressure ventilation in trauma subjects with acute respiratory failure. Monaldi Arch Chest Dis 1999;54(2):109-114.

40. Meduri GU, Turner RE, Abou-Shala N, Wunderink R, Tolley E. Noninvasive positive pressure ventilation via face mask: first-line intervention in subjects with acute hypercapnic and hypoxemic respiratory failure. Chest 1996;109(1):179-193.

41. Conti G, Cavaliere F, Costa R, Craba A, Catarci S, Festa V, et al. Noninvasive positive-pressure ventilation with different interfaces in patients with respiratory failure after abdominal surgery: a matchedcontrol study. Respir Care 2007;52(11):1463-1471. 